\title{
LEY 6/2007, DE 24 DE OCTUBRE, DE REFORMAS URGENTES DEL TRABAJO AUTÓNOMO
}

\author{
Sira Pérez Agulla \\ Departamento de Derecho \\ del Trabajo y de la Seguridad Social \\ Facultad de Derecho \\ Universidad Complutense de Madrid \\ siperez@der.ucm.es
}

\section{CONSIDERACIONES PREVIAS}

El día 25 de octubre de 2017 se publicó en el BOE la Ley 6/2017, de 24 de octubre, de Reformas Urgentes del Trabajo Autónomo ${ }^{1}$. Se trata de una ley oportuna si tenemos en cuenta el relevante papel que hoy juega el trabajo autónomo en el funcionamiento de cualquier economía de mercado y, en particular, en el mercado laboral. Esta relevancia se confirma si tenemos presente su significativa capacidad de recuperación respecto a la crisis económica, alcanzando a día de hoy cifras superiores a los tres millones de trabajadores por cuenta propia. El paso del colectivo por la coyuntura económica, si bien fue nefasto - al igual que para los trabajadores asalariados-, resultó menos duradero en el tiempo, reponiéndose antes, al tocar fondo a principios de 2013. Dicha premura a la hora de superar tan compleja situación dio lugar a que un número importante de antiguos trabajadores asalariados vieran en el trabajo independiente un canal para introducirse de nuevo en el mercado de trabajo. Si bien esta vía alternativa ha resultado favorable, quizá ha influido de manera negativa en el tipo de medidas adoptadas hasta la Ley 6/2017 en favor del colectivo, las cuales, encaminadas principalmente a facilitar el acceso al empleo, obviaron aquellas dirigidas a su mantenimiento, no incidiendo en las dificultades de supervivencia a las que el colectivo se enfrenta. La nueva norma parece tener presente, en mayor medida, las peculiaridades de este tipo de trabajo; además, a pesar

Esta norma parte de la Proposición de Ley de Reformas Urgentes del Trabajo Autónomo presentada por el Grupo Parlamentario Ciudadanos y publicada el 18 de noviembre en el Boletín Oficial de las Cortes Generales. 
Sira Pérez Agulla Ley 6/2007, de 24 de octubre, de reformas urgentes del trabajo...

de centrarse principalmente en cuestiones propias de la Seguridad Social, también se detiene en otros asuntos tales como reducción de cargas económicas y administrativas para este colectivo.

\section{ANTECEDENTES}

Como ya hemos puesto de relieve, la Ley objeto de análisis continua la senda de otras que al igual que ella intentaron mejorar las condiciones de trabajo de los autónomos con posterioridad a la Ley 20/2007, de 11 de julio, del Estatuto del Trabajo Autónomo. Debemos recordar, en los primeros años, normas emblemáticas como la Ley 32/2010, de 5 de agosto - revisada posteriormente por la Ley 35/2014_, que se hizo cargo de una de las medidas más sugestivas y complejas reclamadas por el colectivo, la prestación por cese de actividad. Con el mismo objetivo que la norma anterior, hacer converger la intensidad de la acción protectora de los trabajadores por cuenta propia con la de los trabajadores por cuenta ajena, la Ley 27/ 2011, de 1 de agosto, sobre actualización, adecuación y modernización del Sistema de Seguridad Social, estableció, por un lado, que las bases medias de cotización del Régimen Especial de Trabajadores Autónomos (en adelante, RETA) experimentarán un crecimiento al menos similar al de las medias del régimen general; por otro, que la protección frente a las contingencias profesionales formará parte de la acción protectora obligatoria de todos los regímenes. Esta última medida, la cual la norma de 2011 condicionaba temporalmente, fue derogada por la Ley 36/2014, de 26 de diciembre, de Presupuestos Generales del Estado para el año 2015.

Mayor intensidad adquirió el establecimiento de este tipo de medidas a partir de la Ley 14/2013, de 27 de septiembre, de apoyo a los emprendedores y su internacionalización, cuya dirección fue seguida por dos leyes cuya entrada en vigor se produjo el mismo día en el año 2015: la Ley 30/2015, de 9 de septiembre, por la que se regula el Sistema de Formación Profesional para el empleo en el ámbito laboral, y la Ley 31/2015, de 9 de septiembre, por la que se modifica y actualiza la normativa en materia de autoempleo y se adoptan medidas de fomento y promoción del trabajo autónomo y de la economía social.

Podemos decir que muchas de las iniciativas recogidas en la nueva Ley parten de lo dispuesto por estas normas, siendo su principal objetivo complementarlas y mejorarlas. Ejemplo de este tratamiento ya iniciado lo encontramos en la Ley de apoyo a los emprendedores y su internaciona- 
lización. Esta norma no sólo inició la ampliación del ámbito subjetivo de la comúnmente conocida tarifa plana — dirigida inicialmente por el Real Decreto-ley 4/2013, sobre medidas de apoyo al emprendedor y de estímulo del crecimiento y de la creación de empleo, a los jóvenes menores de treinta años-, sino que también, al igual que hace la nueva Ley, abordó la regulación de la cotización de los trabajadores autónomos en régimen de pluriactividad, reduciendo la base mínima de cotización a los trabajadores incluidos en el RETA que causasen alta por primera vez en el régimen especial y con motivo de la misma se iniciase una situación de pluriactividad, con jornada laboral a tiempo completo o a tiempo parcial superior al 50 por 100 de la jornada a tiempo completo.

Con relación a la Ley 30/2015, de 9 de septiembre, por la que se regula el Sistema de Formación Profesional para el empleo en el ámbito laboral, simplemente debemos apuntar que su art. 23 representa el germen de las medidas incluidas en la nueva norma referentes a la formación profesional para el empleo de los autónomos. Además, también contempla asuntos tales como la determinación de la representatividad de las asociaciones de trabajadores autónomos y la participación de éstos en programas de formación e información de prevención de riesgos laborales, del mismo modo revisados por la Ley 6/2017.

Por lo que se refiere a la Ley $31 / 2015$, de 9 de septiembre, por la que se modifica y actualiza la normativa en materia de autoempleo y se adoptan medidas de fomento y promoción del trabajo autónomo y de la economía social, hay que afirmar que ésta sería la encargada de reunir en un solo texto medidas e incentivos establecidos en favor de los autónomos por otras normas precedentes, llevando a cabo la actualización del texto originario de la Ley del Estatuto del Trabajador Autónomo (en adelante, LETA). Si bien el trabajo de compilación llevado a cabo por la norma es relevante, no podemos obviar que la misma mejoró las medidas existentes e introdujo otras nuevas de gran interés no sólo para los autónomos en funcionamiento, sino también para los nuevos autónomos que emprenden un negocio.

A modo de ejemplo, vemos como ésta, al igual que hace la nueva ley, focalizó su atención en la conciliación de la vida laboral y profesional. No sólo estableció una bonificación del 100 por 100 de la cuota para aquellos trabajadores autónomos sustituidos durante los periodos de descanso por maternidad, adopción, acogimiento, paternidad, riesgo durante el embarazo o riesgo durante la lactancia natural, mediante contratos de interinidad celebrados con desempleados conforme al Real Decreto-ley 11/1998, de 4 de septiembre, sino que también autorizó a los trabajadores autó- 
Sira Pérez Agulla Ley 6/2007, de 24 de octubre, de reformas urgentes del trabajo...

nomos económicamente dependientes a la contratación de trabajadores por cuenta ajena en aquellos supuestos en los que la interrupción de la actividad por causas vinculadas a la conciliación de su actividad profesional con su vida familiar pudiese ocasionar la resolución del contrato con su cliente.

\section{ESTRUCTURA Y NOVEDADES DEL TEXTO. ALGUNOS ASPECTOS DE ESPECIAL RELEVANCIA}

La Ley 6/2017, de 24 de octubre, consta de catorce artículos agrupados en siete títulos, siete disposiciones adicionales, una disposición derogatoria única y trece disposiciones finales. De esta forma, la estructura de la norma es la siguiente:

TÍTULO I. Medidas para facilitar la cotización a la Seguridad Social y para reducir las cargas administrativas de los trabajadores autónomos.

TÍTULO II. Medidas de fomento y promoción del trabajo autónomo.

TÍTULO III. Medidas para favorecer la conciliación entre la vida familiar y laboral de los trabajadores autónomos.

TÍTULO IV. Derechos colectivos del trabajador autónomo.

TÍTULO V. Medidas para clarificar la fiscalidad de los trabajadores autónomos.

TÍTULO VI. Medidas para mejorar la cotización de los trabajadores autónomos.

TÍTULO VII. Medidas para mejorar la formación profesional para el empleo de los trabajadores autónomos.

TÍTULO VIII. Equiparación a efectos de las contingencias derivadas de accidente de trabajo in itinere.

Disposiciones adicionales.

Disposición derogatoria única.

Disposiciones finales.

A grosso modo diremos que las normas recogidas en su articulado, en cuanto a su ámbito subjetivo, se separan entre aquellas dirigidas al colectivo en su totalidad y las orientadas a proteger a grupos específicos dentro del conjunto de los trabajadores autónomo. En cuanto a su momento de aplicación, la norma también preveía dos grupos: aquellas iniciativas de 
aplicación inmediata y otras cuya puesta en marcha se posponía hasta el 1 de enero de 2018 y que, a día de hoy, ya están siendo aplicadas.

Viéndonos en la obligación de abordar el comentario de esta Ley de manera sucinta, debido a la extensión limitada del presente estudio, expondremos de forma esquemática las novedades aportadas por la misma. Para ello dividiremos este apartado en función de la temática abordada por la nueva norma, que si bien dedica la mayor parte de su articulado a cuestiones que giran en torno a la Seguridad Social, también trata otros temas de interés.

\section{Medidas de Seguridad Social}

A pesar de que la aproximación entre regímenes es un hecho, siguen existiendo importantes diferencias entre la protección real recibida por los autónomos y aquella otorgada a los asalariados. Resulta evidente que estas desigualdades responden principalmente a las particularidades propias del tipo de trabajo. Mientras que en la esfera laboral es el empresario el que asume determinadas obligaciones-afiliación, alta y cotización-, cuando de trabajadores autónomos se trata, tales responsabilidades inciden directamente sobre ellos. Además, el modelo de cotización presente actualmente en el RETA se fundamenta en la voluntariedad en el momento de elegir la base de cotización, optando, la mayor parte del colectivo, por elegir la base mínima. Esta elección explica, en gran medida, el por qué el importe medio de las pensiones de este régimen se encuentra en niveles muy por debajo del que arroja el régimen general. Quizá todo ello se deba a que conseguir una protección equivalente a la ofrecida por el régimen general le obligue a soportar un coste fijo de difícil asunción, especialmente en determinadas situaciones en las que tal dificultad se ve acrecentada, por ejemplo, en el comienzo de la actividad o en tiempos de crisis, en el que el acceso al crédito resulta complicado. Por todo ello, es decir, por las particularidades que este colectivo presenta, como ya hemos apuntado, desde la LETA muchas han sido las cuestiones que se han modificado del RETA tanto relativas a la acción protectora como en materia de cotización o, incluso, temas de gestión, No obstante, algunas de las iniciativas apuntadas por normas precedentes bien requerían de un posterior desarrollo o bien quedaban sujetas a un plazo. Precisamente esto es lo que la Ley 6/2017 principalmente vino a hacer, es decir, completar el trabajo iniciado con anterioridad. 
Sira Pérez Agulla Ley 6/2007, de 24 de octubre, de reformas urgentes del trabajo...

Aunque la norma no recoge de manera sistematizada las cuestiones relativas a la Seguridad Social, sino que éstas se entremezclan con otras referentes a otros temas, con el fin de clarificar los principales asuntos que la nueva Ley aborda examinaremos este asunto en función de las principales temáticas modificadas: afiliación, altas y bajas; cotización; deudas a la Seguridad Social; encuadramiento de familiares del trabajador autónomo, $\mathrm{y}$ medidas en materia de prestaciones.

\section{A. Modificaciones relativas a la afiliación, altas y bajas (entraron en vigor el 1 de enero)}

Mediante la disposición final primera de la Ley 6/2017 se lleva a cabo la modificación del reglamento general sobre inscripción de empresas y afiliación, altas, bajas y variaciones de datos de trabajadores en la Seguridad Social, aprobado por el Real Decreto 84/1996, de 26 de enero, a partir de la cual se permitirán diversas altas y bajas en el año dependiendo, lógicamente, de la existencia o no de actividad. Concretamente, tres de ellas surtirán efectos desde el día que se producen y exactamente lo mismo para tres bajas. Con esta modificación se evita cotizar por el mes concreto, acercando al autónomo a la situación del asalariado. La regulación continuará igual para el resto de altas y bajas, las cuales seguirán surtiendo efectos desde el día primero y último del mes en que se producen, respectivamente.

\section{B. Modificaciones relativas a la cotización}

a) Determinación de las bases de cotización

(entró en vigor el 1 de enero de 2018)

A partir de la disposición final segunda de la Ley 6/2017, que vino a alterar el contenido del Reglamento general de cotización y liquidación de otros derechos de la Seguridad Social, se permite al trabajador autónomo cambiar su base de cotización hasta cuatro veces al año (frente a las dos precedentes). Tal modificación se podrá hacer cada trimestre, no requiriendo una causa justificada. Lo que se pretende con este cambio es que el autónomo pueda adaptar mejor su base a sus ingresos, no teniendo que quedar vinculada ésta por largos periodos, sino sólo por tres meses. 
Sira Pérez Agulla Ley 6/2007, de 24 de octubre, de reformas urgentes del trabajo...

b) Cotización a la Seguridad Social en los supuestos de pluriactividad (entró en vigor el 1 de enero de 2018)

El art. 2 de la Ley 6/2017 presta atención a la devolución del exceso en la cotización en los supuestos de pluriactividad. Como ya apuntamos, se trata de un asunto abordado con anterioridad por la Ley 14/2013, de apoyo a los emprendedores y su internacionalización, por la que se había reducido la base mínima de cotización a los trabajadores incluidos en el RETA que causasen alta por primera vez en el régimen especial y con motivo de la misma se iniciase una situación de pluriactividad, con jornada laboral a tiempo completo o a tiempo parcial superior al 50 por 100 de la jornada a tiempo completo. En cuanto a esta cuestión, y tras la modificación de la Ley General de la Seguridad Social a partir de la nueva norma, no será necesario que el trabajador autónomo solicite y demuestre el exceso de cotización; será la Seguridad Social, de oficio, la que devolverá antes del 1 de mayo del siguiente año el exceso de cotización.

c) Reducciones y bonificaciones de cuotas a favor

de los trabajadores autónomos a través de la tarifa plana

(entró en vigor el 1 de enero de 2018)

El art. 3 de la nueva norma viene a modificar el art. 31 de la Ley 20/2007, de 11 de julio, del Estatuto del Trabajo Autónomo, en lo referente a la vulgarmente conocida como tarifa plana; en particular, se amplía de seis a doce meses la cuota reducida para los autónomos que emprendan o reemprendan una actividad por cuenta propia. Del mismo modo, se reduce el plazo de cinco a dos años sin cotizar en el RETA para poder beneficiarse de la misma o de cinco a tres años en el supuesto de haber disfrutado con anterioridad de esta ventaja. La Ley, en su art. 7, por el que se añade un nuevo art. 38 bis a la Ley 20/2007, introduce un nuevo supuesto de tarifa plana para aquellas mujeres autónomas que retornen a una actividad por cuenta propia dentro de los dos años siguientes a la fecha de cese por descanso por maternidad, adopción, guarda con fines de adopción, acogimiento o tutela. 
Sira Pérez Agulla Ley 6/2007, de 24 de octubre, de reformas urgentes del trabajo...

d) Bonificación a los trabajadores por cuenta propia por conciliación de la vida laboral y personal (entró en vigor el 26 de octubre de 2017)

Junto a este último supuesto señalado en el apartado anterior, la Ley 6/2017 lleva a cabo una serie de modificaciones en favor de la conciliación de la vida laboral y personal:

- A partir de su art. 5 se modifica el art. 30 LETA. Así, la bonificación del 100 por 100 de la cuota de autónomos por contingencias comunes durante doce meses por cuidado de menores de siete años se amplía hasta menores de doce años. No podemos obviar que dicho beneficio también puede ser disfrutado en caso de que el trabajador por cuenta propia tenga a su cargo un familiar por consanguinidad o afinidad hasta segundo grado en situación de dependencia debidamente acreditada, como un familiar del mismo grado con parálisis cerebral, enfermedad mental, discapacidad intelectual reconocida igual o superior al 33 por 100 o discapacidad física o sensorial superior a un 65 por 100. Del mismo modo, resulta de interés recordar que su disfrute queda condicionado: en primer lugar, a la permanencia del autónomo en el RETA; en segundo lugar, a la contratación de un trabajador a tiempo completo o parcial (en este caso por una jornada laboral igual o superior al 50 por 100 de la jornada de un trabajador a tiempo completo) que realice su misma actividad; en tercer lugar, a que dicho contrato dure al menos tres meses contados desde el inicio del disfrute de la bonificación, y, por último, el trabajador autónomo que se beneficie de esta bonificación deberá mantenerse en alta en la Seguridad Social durante los seis meses siguientes al vencimiento de disfrute de la misma.

- Mediante su art. 6 la Ley modifica el art. 38 LETA referente a la bonificación de cuotas de Seguridad Social para trabajadores autónomos durante el descanso por maternidad, paternidad, adopción, guarda con fines de adopción, acogimiento, riesgo durante el embarazo o riesgo durante la lactancia natural. Tras la reforma, la bonificación se amplía al supuesto de guarda con fines de adopción; además, ya no es requisito imprescindible la simultánea sustitución del trabajador por cuenta propia a través de un contrato de interinidad bonificado, el cual continúa siendo compatible. 
Sira Pérez Agulla Ley 6/2007, de 24 de octubre, de reformas urgentes del trabajo...

C. Modificación de los recargos por ingresos de deudas

de Seguridad Social fuera de plazo

(entró en vigor el 1 de enero de 2018)

El art. 1 de la Ley del Trabajo Autónomo modifica el art. 30 de la Ley General de Seguridad Social reduciendo con ello el recargo por ingresos de deudas de Seguridad Social fuera de plazo. Anteriormente, el recargo era siempre del 20 por 100. Tras la reforma, si las cuotas se abonan dentro del primer mes natural siguientes al del vencimiento del plazo para su ingreso será sólo del 10 por 100 y si es posterior, continúa siendo el 20 por 100.

\section{Modificación en relación con el encuadramiento de familiares del trabajador autónomo y bonificaciones en la cotización (disposición adicional séptima) (entró en vigor el 26 de octubre)}

a) Bonificaciones a la contratación de familiares del trabajador autónomo

De conformidad con el art. 35 LETA, la contratación indefinida por parte del autónomo como trabajadores por cuenta ajena de su cónyuge, ascendiente o descendiente hasta segundo grado dará derecho a una bonificación en la cuota empresarial por contingencias comunes del 100 por 100 durante doce meses. Para poder acogerse a este beneficio es necesario que se den una serie de condiciones:

- que el trabajador autónomo no hubiera extinguido, bien por causas objetivas o despidos disciplinarios que hayan sido considerados judicialmente improcedentes en los doce meses anteriores a la celebración del contrato que da derecho a la bonificación;

- que se mantenga el nivel de empleo en los seis meses posteriores a la celebración de la contratación que da derecho a la bonificación.

Pues bien, la disposición final octava de la nueva Ley modifica dicho artículo y extiende la bonificación a la pareja de hecho del autónomo; además, clarifica lo que se entiende a estos efectos por pareja de hecho y la forma de acreditar la existencia de dicha unión. 
Sira Pérez Agulla Ley 6/2007, de 24 de octubre, de reformas urgentes del trabajo...

b) Encuadramiento en la Seguridad Social de hijos del trabajador autónomo (en particular, hijos discapacitados)

La disposición final sexta de la nueva Ley incide en la modificación realizada por la Ley 27/2009, de 30 de diciembre, a partir de la cual se añadió a la disposición adicional décima un párrafo por el que se extendía este posible encuadramiento a los hijos que, aun siendo mayores de treinta años, tuvieran especiales dificultades para su inserción laboral. A estos efectos, se consideró que existían dichas especiales dificultades cuando el trabajador estuviera incluido en alguno de los grupos siguientes:

- Personas con parálisis cerebral, personas con enfermedad mental o personas con discapacidad intelectual, con un grado de discapacidad reconocido igual o superior al 33 por 100.

- Personas con discapacidad física o sensorial, con un grado de discapacidad reconocido igual o superior al 65 por 100 .

Pues bien, la disposición final sexta de la Ley 6/2017 extiende la posibilidad de contratación de hijos mayores de treinta años a aquellos con discapacidad física o sensorial con un grado de discapacidad reconocido igual o superior al 33 por 100 e inferior al 65 por 100 .

\section{E. Medidas en materia de prestaciones}

a) Accidente in itinere (entró en vigor el 26 de octubre de 2017)

El art. 14 de la nueva Ley modifica el art. 316.2 LGSS respecto de la cobertura de contingencias profesionales, incorporando con carácter general a la misma el accidente in itinere, antes sólo previsto para los trabajadores autónomos económicamente dependientes.

A estos efectos se entiende como lugar de la prestación el establecimiento en donde el trabajador autónomo ejerza habitualmente su actividad siempre que no coincida con su domicilio y se corresponda con el local, nave u oficina declarado como afecto a la actividad económica a efectos fiscales. 
Sira Pérez Agulla Ley 6/2007, de 24 de octubre, de reformas urgentes del trabajo...

b) Compatibilidad de la realización de trabajos por cuenta propia con la percepción de una pensión de jubilación contributiva (entró en vigor el 26 de octubre de 2017)

La disposición final quinta de la Ley 6/2017 modifica el art. 214 Ley General de la Seguridad Social (en adelante, LGSS). Como venía ocurriendo hasta el momento, la cuantía de la pensión de jubilación compatible con el trabajo será del 50 por 100 del importe resultante de la pensión, cualquiera que sea la jornada laboral o la actividad que realice el pensionista. Tras la modificación, si la actividad la realiza un trabajador autónomo persona física (se excluyen a los societarios) y se acredita tener contratado, al menos, a un trabajador por cuenta ajena, la cuantía de la pensión compatible con el trabajo alcanzará el 100 por 100 del importe de la pensión. Por otro lado, se establece el compromiso, dentro del ámbito del diálogo social y de los acuerdos en el seno del Pacto de Toledo, de extender esta posibilidad al resto de la actividad por cuenta propia y al trabajo por cuenta ajena.

\section{Otras cuestiones}

Además de los múltiples temas abordados por la reforma en materia de Seguridad Social, otras cuestiones han sido también revisadas por la Ley 6/2017. Así, teniendo presente la extensión de este estudio, ahondaremos de manera breve en dos de estos asuntos en cuyo tratamiento parece desprenderse un especial interés por parte del legislador; en particular, nos referimos a los derechos colectivos adjudicados al colectivo, a la posible deducibilidad de los gastos en los que incurren los trabajadores por cuenta propia en su actividad, así como a la formación profesional para el empleo de los mismos.

\section{A. Derechos colectivos (26 de octubre de 2017)}

Las novedades introducidas por el título IV de la Ley 6/2017 afectan a los arts. 19, 20 y 22 LETA, a los cuales les otorga una nueva redacción clarificando determinadas cuestiones.

El art. 8 de la nueva norma modifica el art. 19.3 LETA para corregir la remisión que el propio precepto efectuaba, en su apartado tercero, al 
artículo donde se regula la determinación de la representatividad de las asociaciones de trabajadores autónomos, esto es, el art. 21.3, y que no se correspondía en su remisión —la hacía al apartado 5- con la redacción vigente tras la modificación llevada a cabo por la Ley 30/2015, de 9 de septiembre, por la que se regula el Sistema de Formación Profesional para el empleo en el ámbito laboral.

Por otro lado, el art. 9 de la novedosa Ley altera la redacción del art. 20.4 LETA, el cual, si bien en su redacción originaria se mostraba inconcreto y difuso al emplear el término «podrán» en referencia a la utilidad pública de las asociaciones de los trabajadores autónomos - conforme a la Ley Orgánica 1/2002-, ahora se fija con claridad qué asociaciones serán declaradas como tales; en particular, se determina que siempre adquirirán dicha condición las asociaciones, confederaciones, uniones y federaciones de trabajadores autónomos de carácter intersectorial que hayan acreditado ser representativas y con mayor implantación, tanto en el ámbito estatal como en el autonómico, en los términos establecidos en el art. 21 de la propia LETA.

En otro orden de cosas, el art. 10 de la Ley 6/2017 ahonda en la composición del Consejo del Trabajo Autónomo Estatal y modifica la redacción de los apartados tercero y séptimo del art. 22 LETA. En particular, contempla la representación en su seno de los Consejos del Trabajo Autónomo de ámbito autonómico e indica que serán éstos los que deberán solicitar su participación y designar un representante, que, en cualquier caso, corresponderá a la asociación de autónomos con mayor representación en ese ámbito.

Respecto a este asunto habría que decir también que estas modificaciones hay que ponerlas en relación con la disposición adicional segunda de la nueva Ley, donde se contiene el mandato dirigido al Gobierno de proceder a la constitución efectiva y puesta en funcionamiento del Consejo del Trabajo Autónomo en el plazo máximo de un año tras la entrada en vigor de la presente Ley en los términos previstos en el art. 22 LETA, así como en el Real Decreto 1613/2010, de 7 de diciembre, por el que se crea y regula el Consejo de la representatividad de las asociaciones profesionales de trabajadores autónomos en el ámbito estatal y se establece la composición y régimen de funcionamiento y organización del Consejo del Trabajo Autónomo. Este mandato se completa con otra obligación hacia el Gobierno sujeta a plazo y recogida en el segundo párrafo de la disposición citada; en particular, se pide al Gobierno que, en el plazo de seis meses y en el marco del diálogo con las organizaciones representati- 
vas de trabajadores autónomos y las organizaciones empresariales y sindicales más representativas, desarrolle los criterios objetivos de representatividad de las organizaciones profesionales de trabajadores autónomos que establece el art. 21 LETA.

Asimismo, todavía cabe apuntar otro mandato al Gobierno, como es el recogido en la disposición adicional primera de la nueva Ley. A partir de esta disposición se encomienda a éste y en el plazo de un año - sin indicar el dies a quo_ la misión de adoptar las medidas que permitan la presencia de los trabajadores autónomos en el Consejo Económico y Social, y cuya consecución habrá de tener en cuenta la evolución del Consejo del Trabajo Autónomo en la representación de dichos trabajadores.

\section{B. Deducibilidad de los gastos en los que incurren los autónomos en su actividad (entró en vigor a partir de 1 enero de 2018)}

El título $\mathrm{V}$ de la nueva Ley introduce diversas modificaciones en el Impuesto sobre la Renta de las Personas Físicas con la finalidad de clarificar la deducibilidad de los gastos en los que incurren los autónomos en el ejercicio de su actividad, de forma que puedan contar con un aceptable grado de seguridad jurídica; en particular, su art. 11 modifica la regla 5. ${ }^{a}$ del apartado 2 del art. 30 de la Ley 35/2006, de 28 de noviembre, del Impuesto sobre la Renta de las Personas Físicas y de modificación parcial de las leyes de los Impuestos sobre Sociedades, sobre la Renta de no Residentes y sobre el Patrimonio. De este modo, tras la modificación, tendrán la consideración de gasto deducible:

- Aquellos referidos a los suministros — agua, electricidad, gas, telefonía, internet - cuando la actividad se desarrolle en una parte de la vivienda habitual del autónomo. Sobre la parte del gasto que corresponda a los metros cuadrados dedicados a la actividad en relación a los totales de la vivienda se le aplica un porcentaje del 30 por 100 .

- Aquellos referidos a la manutención del propio contribuyente incurridos en el desarrollo de la actividad económica. La deducción de estos gastos queda sometida al cumplimiento de dos requisitos:

- Que se produzcan en establecimientos de restauración y hostelería.

- Que se abone utilizando cualquier medio electrónico de pago. 
Sira Pérez Agulla Ley 6/2007, de 24 de octubre, de reformas urgentes del trabajo...

Además, la norma establece que el importe deducible por este concepto tendrá como límite diario las mismas cuantías que para gastos de manutención se establecen para trabajadores por cuenta ajena en el Reglamento del Impuesto sobre la Renta de las Personas Físicas, esto es, con carácter general, 26,67 euros diarios si el gasto se produce en España o 48,08 euros si es en el extranjero, cantidades que, a su vez, se duplican si además, como consecuencia del desplazamiento, se pernocta.

\section{Formación profesional para el empleo del trabajador autónomo}

El título VII de la nueva Ley, en particular su art. 13, establece la participación de las organizaciones intersectoriales representativas de autónomos y de la economía social en la detección de necesidades, diseño, programación y difusión de la oferta formativa para trabajadores autónomos a la que hace referencia la Ley 30/2015, de 9 de septiembre, por la que se regula el Sistema de Formación Profesional para el Empleo en el ámbito laboral; actividades que se financiarán de la forma y con las limitaciones establecidas en la citada norma.

Por otro lado, y conectado tanto con la participación de los trabajadores autónomos como con las acciones formativas, mediante la disposición adicional octava de la Ley objeto de análisis, en el ámbito de la prevención de riesgos laborales, se modifica la disposición adicional duodécima de la LETA para que las asociaciones intersectoriales de estos trabajadores, tanto a nivel estatal como autonómico, puedan participar — con voz pero sin voto- en los grupos creados en el seno de la Comisión Nacional de Seguridad y Salud en el Trabajo cuando se aborden cuestiones que, en este ámbito, les incumban.

\section{Trabajo de la Subcomisión del Congreso}

Cuestiones relevantes se encuentran en fase de estudio en el seno de la Subcomisión parlamentaria del Congreso para el estudio de la reforma del Régimen Especial de Trabajadores Autónomos (RETA). Esta Comisión se constituye como la encargada de abordar cambios más profundos en este sistema, en particular:

- La disposición adicional cuarta de la nueva Ley incluye el concepto de habitualidad entre las cuestiones a estudiar en el ámbito de 
la Subcomisión, principalmente a los efectos de la inclusión de los trabajadores por cuenta propia cuyos ingresos no superen el SMI.

- La disposición adicional quinta encarga a la Subcomisión la determinación de los diferentes elementos que hagan posible la implantación de un sistema de cotización a tiempo parcial para los trabajadores autónomos mediante el oportuno desarrollo reglamentario del art. 25 de la Ley 20/2007, de 11 de julio, del Estatuto del Trabajo Autónomo, para las actividades o colectivos que se consideren, y en todo caso vinculado a periodos concretos de su vida laboral.

- Por último, la disposición adicional sexta encomienda a dicha Subcomisión la determinación de los diferentes elementos que hagan posible el acceso a la jubilación parcial de los trabajadores del RETA, incluida la posibilidad de contratar parcialmente o por tiempo completo a un nuevo trabajador para garantizar el relevo generacional en los supuestos de trabajadores autónomos que no cuentan con ningún empleado.

\section{REFLEXIONES FINALES}

Para finalizar esta breve exposición de la última reforma llevada a cabo en materia de trabajo autónomo, debemos decir que la misma no es más que la continuación de los paquetes de medidas de apoyo al colectivo que, tras la entrada en vigor de la Ley 20/2007, de 11 de julio, del Estatuto del Trabajo Autónomo, se han venido sucediendo periódicamente. Si bien valoramos positivamente la nueva Ley y celebramos, particularmente, ciertas medidas en cuya fijación el legislador, por fin, parece haber tenido presente las particularidades propias de este tipo de trabajo, no podemos dejar de considerar que muchas otras iniciativas resultan criticables por beneficiar únicamente a una parte del colectivo. Además, tradicionales reivindicaciones vuelven a quedar desatendidas; ejemplo de ello, la posibilidad de cotizar por ingresos reales, tan reclamada al Gobierno por las principales asociaciones de trabajadores autónomos. Así mismo, la Ley no concluye iniciativas recogidas en normas anteriores que, necesitadas de un desarrollo posterior, actualmente continúan sujetas a plazo; esto es lo que sucede, por ejemplo, con la constitución del Consejo del Trabajo Autónomo o la posibilidad de pertenencia del colectivo en el Consejo Económico y Social, ambas planteadas hace una década por la LETA y hoy, todavía, en proceso de consecución. 
Sira Pérez Agulla Ley 6/2007, de 24 de octubre, de reformas urgentes del trabajo...

Por otro lado, el legislador de la Ley parece obviar la transcendencia de alguna de las medidas implantadas y sus posibles efectos respectos de otras normas. La más llamativa, la regulación otorgada a los familiares de los trabajadores autónomos, la cual parece no casar con el contenido de la LETA o incluso con el del Estatuto de los Trabajadores. Por último, se echa de menos una revisión de la figura del Trabajador Autónomo Económicamente Dependiente (TRADE); la nueva Ley obvia a este trabajador de tal manera que ni siquiera prevé la modificación del art. 11.2.a).3 LETA en consonancia con la ampliación que lleva a cabo de la edad del menor a cuidar. 